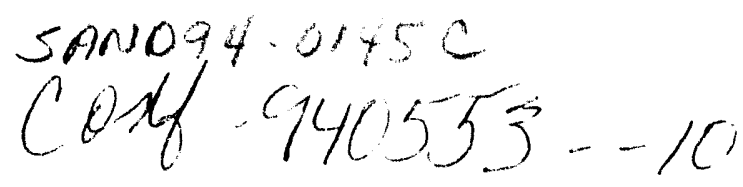

\title{
A COMPARISON OF SPENT FUEL SHIPPING CASK RESPONSE TO 10 CFR 71 NORMAL CONDITIONS AND REALISTIC HOT DAY EXTREMES
}

\author{
Sreven James Manson \\ The University of Texas at Austin \\ Collesge of Engincering \\ Ausin, TX 78712 \\ (512) 471-3119
}

\author{
Steven Eric Gianoulakis \\ Sandia National Laboratories \\ Mail Stop 0835 \\ Albuquerque, NM 87185 \\ (505) 844.0450
}

\begin{abstract}
The structural properties of spent nuclear fuel shipping conmivers vary as a function of the cask wall temperatme. An analysis is performed to determine the effect of a realtitic, though bounding, hot day environment on the themal behavior of spent fuel shipping casto. These results are compared to those which develop under a steady-state application of the prescribed nomblal thermal conditions of 10CFR71. The completed analysis revealed that the majority of wall cemperaures, fir a wide variety of spent fuel shipping cask configurations, fall well below those predicted by using the steady-state applieation of the regulatory boundary conditions. It was found that maximum temperawres at the cask surface occasionally lie above temperawres predicted under the regulatory condition. This is due to tie conservative assumptions present in the ambient conditions used. The analysis demonstrates that diumal cemperature variations which penemate the cask wall have maximn substancially less than the corresponding temperatures obtained when applying the steady-state regulawory boundary conditions. Therefore, it is cermin that vial cask components and the spent fuel itself will not ev:ceed the temperatures calculated by use of the steady-sture interpretation of the 10CFR71 normal conditions.
\end{abstract}

\section{NTRODUCHON}

The U. S. Niuclear Regulatory Commission (NRC) has specified th: normal thermal conditions under which spent fuel shipping containers are to be evaluated in Tidle 10 of the Code is Federal Regulations, Section 71 (10CFR71). The regulation specifies an ambient temperature of :18 ${ }^{\circ} \mathrm{C}\left(100^{\circ} \mathrm{F}\right)$, and a daily lotal insolation of $800 \mathrm{caV} / \mathrm{cm}^{2}$, which is to be deposited over a twelve hour period. Orie frequently used interpretation of the insolation regulution assumes that the solar flux is steady, at a rate of $67 \mathrm{cal} / \mathrm{cm}^{2} / \mathrm{hr}$. As the specified ambient temperature and steady-staic solar flux are somewhat lower than peaks oflen reached in some regions of the country, it has been deemed valuable to compare the effects of an hourly varying realistic, though bounding (sec Section II), ambient cycle to those of the regulation as implemented. This suidy will undertake a comparison of cask response to two sets of ambient conditions, and examine two different realisric cask designs in order to draw conclusions about the general differences between the regulatory and realistic conditions.

Previous sudies by Lake have shown that the NRC's hot day thermal condition is adequate for predicting the thermal response of the interior regions of large watercooled shipping casks. ${ }^{1}$ It has also been shown by Brown that the thermal response of the surface regions of casks characterized as simple steel plates are reasonably well represented by utilization of the normal condition of 10CFR71.2 Actual cask designs, however, are laminations of several concentric shells with widely varying thermal properties, and hence much more complicated than the steel plates studied by Brown. Furthermore, the studies by Lake and Brown use only simple mathematical functions to represent postulated environmental data. It is thought that by utilizing ectual hot day data, a more realistic analysis may be performed. Lastly. Brown's analysis used a lumped-parameter model. It is felt that more exact conclusions may be drawn by modeling the spatial propagation of thermal effects through the cask wali, especially in situations involving multiple layers of cask material.

The imporant difference between the regulations as cired, and the actual typical meteorological conditions, is two-fold. First, there is the matter of the peak values of temperature and insolation, which both may be potentially larger than the stated regulatory condition. Second, the nature of the diumal variacion of both the temperature and

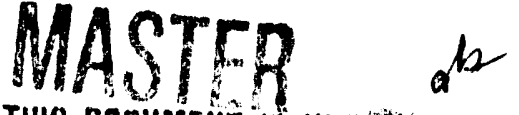

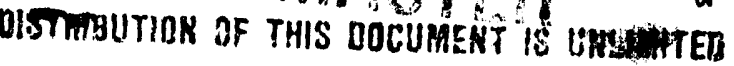

This work was supnorted by the United

States Department of Energy under

Contract DE-ACn4-94ALR5ño. 


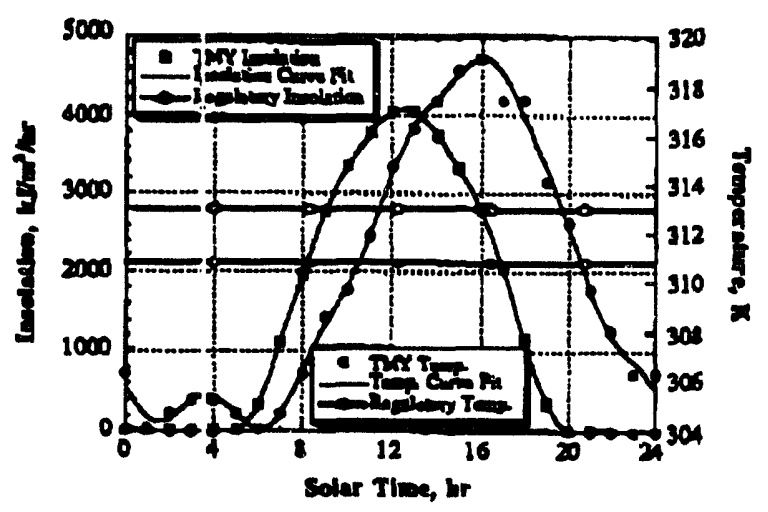

Figure 1: TMY Hot Day Data

insolation rate suggests that transient themnal behavior not predieted by the steady-state interpretation of the regulatory model may occur. These effects compete to a centain extent, and decoiled analysis can ywantify the overall thermal sehavior of transport casks subjected to diumal variation in ambient condicions.

If is crucial to point out that the analyses described berein have beeil carried out with very realistic ambient conditions and cask designs. The heat load emanating from the spent fiel will not change the relative profiles of the realistic and regulatory cases even if the heat load is varied drastically. However, variation of the heat source will change the :nagnimides of the temperatures within the cask walls quile significantly. Thus, it must be noted that the temperature profiles calculated for discussion in this section are to be viewed only with regard to comparisons of the relative elfects of the realistic and regulatory conditions, and should not in any way be construed as predictions of axtual temperatures in transport siouadions. Therefore, if any specific temperature within any cask wall is shown as exceeding the specific regulatory guidclines for the temperanures of corresponding cask components, thi: must nol be laken as a weakness of the cask design, the computational algorithm, or of this analysis. The celculations which demonsurate compliance with specific teniperature regulations are the domain of cask manufacturers and are ontside the scope of this report

\section{DESCRIPTIIN OF THE WORK}

The meteonilogical data which was used in this study has been compiled by the National Climatic Data Center (NCDC). The NCDC has gathered weather data from all over the U.S. Ovis a period of 27 years and combined it in a series of recorts cumulatively referred to as the Typical Meleorological Year (TMY). The daca of specific coneem for this : thudy are the solar radiation measurements aid the temperature. The characterization of insolation and temperature together will allow the adequate formulation of a thermal boundary condition for the surface of a cask.

All available TMY daca were searched in order to locate each day in which the integrated radiation flux (tolal nuence) was a maximum. A similar search was conducted to find the maximum lemperature in the U.S. TMY. The worst case day for insolation in the TMY data was found to be for Dodge City, Kansas, on May 29 $\left(834.4 \mathrm{cal} / \mathrm{cm}^{2}\right)$. The hottes! day in the TMY was recorded for Yuma, Arizons, on July $10\left(\right.$ hex $\left.=46^{\circ} \mathrm{C}\right)$. The TMY data for these days are shown in Figure 1.

The measurements provided in the TMY data sets are recorded in hourly increments, however, a reallstic thermal simulation which utilizes this data will have a time step smaller than one hour. It becomes neceseary to inverpolate the data in some manner, in order to provide insolation or temperature boundary condirions at any instant over the course of a day. There is an abundance of interpolation routines which may prove useful for the present application. However, due to the general shape of the dan, the Cosine Fourier Transformation (CFI) was chosen for use in cvaluating the data. The CFT is particularly suitable due to its inherent ability 10 cvaluate the derivative of 2 function once CFT of the function is known." This ability is helpful when evaluating the insolation data, since the TMYY data provides measurements of the insolation fluence during each hour previous to the recording of the measurement, which is cffectively the integral of the radiation flux. Thus, the insolation rate may be recovered from the data by taking the derivative of the fluence value. The CFT curve fits of the TMY data are also shown in Figure 1.

The CFT function of temperaure has been smoothed in order to eliminate the small order oscillations present in the data. The peak lemperalure has been preserved, as wcll as the general form of the diumal variation, however, smaller oscillations which do not contribute to the general, overall diumal behavior are eliminated. Had the small oscillations been retained, physically unrealistic "wiggles" in the CFT interpolation would have resulted. The smoothing was performed by canceling 20 (out of 48 ) of the higher order terms of the CFT by setting their cofficients equal to zero. These coefficients cortespond to cosine waves with the smallest periods, and hence are most responsible for the extremely localized "wiggling."

\section{A. Heat Conduction Model}

In order to determine the penecrative effexts of the diurnal variation of temperature and insolation, and thereby the maximum temperature profile through the cask wall, it was necessary to formulate an appropriare transient heat conduction model. The model accuratcly represents the geometry of interest, is one-dimensional and time accurate. A complete description of the 
numerical modil may be found in the repor which was the foundation if this paper.s

The general one-dimensional transient heat conduction equition in cylindrical coordinates is given ast:

$$
\frac{1}{\tau} \frac{\partial}{\partial \tau}\left(r k_{\tau} \frac{\partial t}{\partial \tau}\right)+q^{m}=p c_{p} \frac{\partial \tau}{\partial \tau}
$$

In this notation. $t$ is temperaure, $\tau$ is time, $r$ is the spatial coordinate, $k$, it the thermal conductivity as a function of $r, q$ ' is the gentreation term, $\rho$ is the material density, and $c_{p}$ is the materisd specific heat

For regions: away from material interfaces, where $k_{m}$ $p$ and $c$, can be urated as constants and with no generation term, the expression may be simplified using the thermai diff usivity, $\alpha=k /\left(p c_{p}\right)$, and the definition of the LaPlacian, in the radial coordinate. Equarion 1 becomes:

$$
\frac{\partial^{2} t}{\partial r^{2}}+\frac{1}{r} \frac{\partial t}{\partial r}=\frac{1}{\alpha} \frac{\partial t}{\partial \tau}
$$

Discretization of this equation yields:

$$
\frac{t_{i+1}-2 t_{i}-t_{i-1}}{\Delta r_{i}^{2}}+\frac{1}{r_{i}} \frac{t_{i-1}-t_{i+1}}{2 \Delta r_{i}}=\frac{1}{\alpha} \frac{t_{i}-t_{i}^{d d}}{\Delta t}
$$

This expression can be solved by a tridiagonal matrix algorithm. The tridiagonal matrix solution algorithm is well documented, 4 and can be implemented successively for transient solutions of Equation 3 on the interior domain of any layer.

As the computational model is transient and onedimensional, it is necessary to define two boundary conditions in acdition to an initial condition. The initial condition is arbitrary because the solution is periodic, thus the simulation continues until all residual cffects of the initial condition have died away. The interior boundary condition is a krown constant heat flux. $q_{p}{ }^{\prime \prime}$, which appears due to the spent nuclear fuel inside the cask. The extermal bound $r y$ condition is formulated from the realistic bounding environmental data. The cuter surface of the spent fuei shipping cask is exposed to a diumally varying ambienl temperature, i which causes convective hear transfer as well as thermal radiation. Furthermore, the surface abscirbs incident solar radiation which along with $t_{m}$ is directly available from the TMY data.

Together the equations for the interior nodes and boundary noder constiture a complete set of governing equations. When these equarions are solved simultareously over time, they yield the transient temperature dis ribution throughout the cask wall. Once the governing e puations have been solved for a twenty. four hour transient, the entive temperature profile in the wall at midnight is compared to that profile which occurred twenty-four hours earlier. This allows the determination of whether the transient solution has become truly priodic. Periodicity will always develop

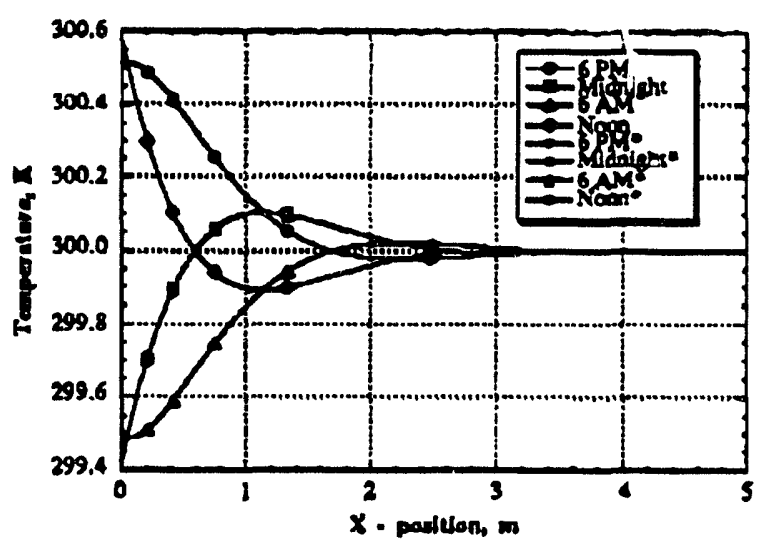

Figure 2: Plot of Numerical and Analytical(") Solutions of the Benchmark Problem

due to the twenty-four hour periodic cycle imposed by the boundary conditions. When the maximum variation in temperature, from midnight to midnight, at every node is less than a specified convergence criterion, a steady periodic solution is said to have been reached. When this oceurs, the code post processes the solution data. If steady periodicity has not yet been achicred. the code relurns 10 increment the time step again and calculate the variation for the next whole day.

\section{B. Validation and Benchmarking}

The computational procedure was verified to ensure the correctness of its derivation, as well as its implementation. The benchmark problem concerns a semi-infinite slab exposed to convection heat transfer, the ambient temperature, $t_{m}$ varying sinusoidally with a given period, $\omega$. An analytical expression for the temperature variation within the slab exists as a function of time and distance into the slab. Given the ambient temperature, tand the convection coefficient, $h$, as well as the material properties of the slab, $k$ and $\alpha$, the temperature response in the slab after some finite time, $\Delta \tau$, may be calculated from an analytically derived formula ar any time in the periodic transient. This benchmark problem was chosen because it is similar to the complex spent fuel container analysis and yet it has a known exact analytical solution.

In this simulation, the semi-infinite slab (a cylinder with an infinite radius) is exposed for a long period of time to a fluid whose temperaure, 1 - is sinusoidally varying with time. The equation representing this temperature oscillation is defined as:

$$
t_{-}(z)=i+t_{1} \cos (\omega \tau)
$$

The amplitude of the variation is given as $r_{0}$, and its frequency is $\omega$. The slab is initially at the mean temperature of the fluid, $i$ throughout so that the transient temperature approaches a constant value of $i$ as $x$ approaches infinity, irrespective of time. The expected solution is a sinusoidally varying temperanure, whose 


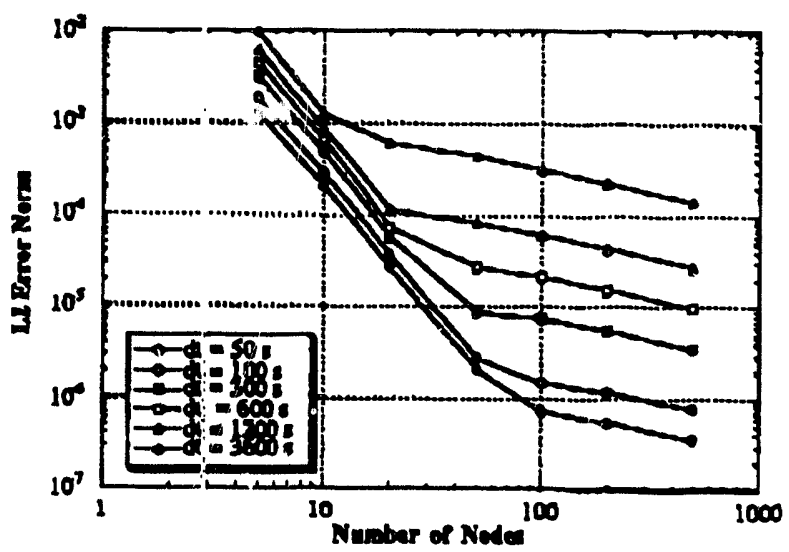

Figure 3: $L_{k}$ Error Norm as a Function of Spatial Discrelization for Various Time Steps

ampliude decays with position in the slab. Furthermore, the sinusoidal behavior at the surface of the slab should exhibit a phase lag behind the ambient Lemperature.

Gebhar prosents the analytical solution to the problestin ${ }^{6}$ one representation of which is presented in Figure 2. The timperature solution as a function of time, $\tau, x$ position, and the frequency of the oscillation, $\alpha$, is:

$$
t(x, \tau)=i+\frac{a t_{a} \exp \left(-x \sqrt{\frac{\omega}{2 \alpha}}\right)}{\sec \left(\cot -x \sqrt{\frac{\omega}{2 \alpha}}-b\right)}
$$

Where:

$$
\begin{aligned}
& a=\sqrt{\frac{1}{s^{2}+2 c+1}} \\
& b=\arctan \left(\frac{c}{c+1}\right)
\end{aligned}
$$$$
\text { and } \quad c=\sqrt{\frac{1 \mathrm{l \omega p} c_{p}}{2 h^{2}}}
$$

The behavior of the analytical and corresponding numerical solutions are shown in Figure 2 for several different values of time, $\tau$, calculated for a discretization with $\Delta x=0.0025 \mathrm{~m}$ and $\Delta t=100 \mathrm{sec}$. These calculations were performed for a semi-infinite slab of steel, $k=60.5$ $W / m / K, \alpha=1.77 \times 10^{-5}, h=10.0 \mathrm{~W} / \mathrm{m}^{2} / \mathrm{K}$. The values needed to specily the ambjent temperanure, $t_{\infty}$ arc $i=$ $300.0 \mathrm{~K}, t_{a}=1 \mathrm{C} .0 \mathrm{~K}$, and $\omega=2 \pi \times 24$ hours. The phase of the ambient tamperature is specified such that the peak ambient tempernture occurs at noon.

The plut in Figure 2 exhibits severl feaures of note. It can be sibserved that, of the four times shown. high levels of hivat flux into and out of the surface $(x=0)$ cecur at noon and midnight, respectively. This is evident because high heat flux into the slab will result in a large

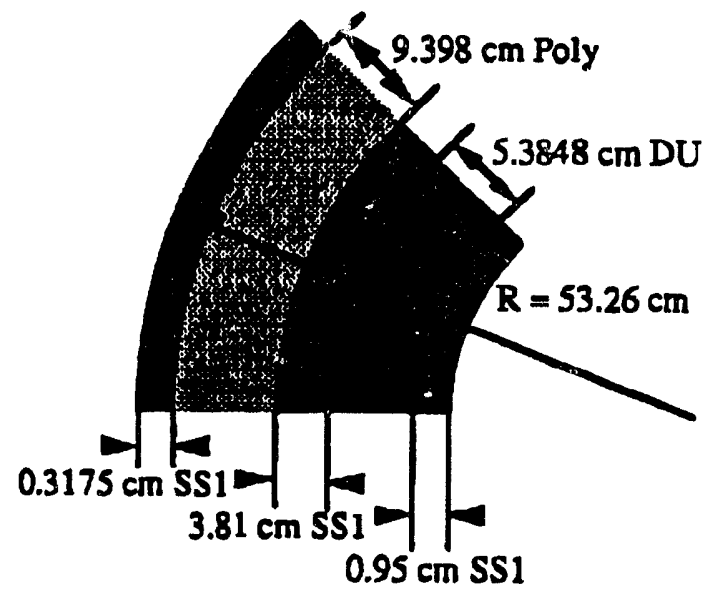

Drawing not to Scale

Figure 4: Schematic Drawing of Generic Truck Cask Wall

negative gradient in temperanure near the surface of the slab. Furthermore, when the ambient temperabure has retumed to $300 \mathrm{~K}$ at both $6 \mathrm{AM}$ and $6 \mathrm{PM}$, the surface flux is near zero (the slope of the temperature at the surface is approximately zero), due to the small temperature difference between the ambient fluid and the steel slab. Figure 2 also demonstrates the level of accuracy of the computational algorithm, as at most points the nunierical simulation cannot be distinguished from the analytical solution. For this benchmark case, the semiinfinite slab is approximated by a slab five meters in width, and the data presented in Figure 2 demonstrates graphically that significant temperature variations do not propagate beyond this distance.

Figure 3 shows the $L_{2}$ error norm of the entire numerical solution in space and time (over an entire 24 hour cycle, and for the entire slab). The $\mathrm{L}_{2}$ norm of the error is defined as:

$$
L_{2}=\frac{\Delta \tau \Delta x}{T X} \sqrt{\sum_{j=1}^{M} \sum_{i=1}^{N}\left[l_{f}\left(x_{i}, \tau_{j}\right)-t_{n}\left(x_{i}, \tau_{j}\right)\right]^{2}} \quad 9
$$

The values $X$ and $I$ represent the total length and time of the computation, respectively (five meters and twentyfour hours), and the subscripts $f$ and $n$ denote the analyrical and numerical solutions, respoctively. The $L_{2}$ norm croor is calculated as a function of spatial discretization for several time steps. Figure 3 demonstrates the convergence of the algorithm, and suggests that the scheme will approach a single solution (equal to the analytical one) through subsequent refinement of spatial and temporal discretization. Temporal error is seen to propargate into the spatial solucion; this effect is manifested in the form of a decrease in the magnitude of the slope of the crror curve in Figure 3 when the spatial discretization is more refined than the temporal discretization. 
Table 1: Thermal Properties of Materials

\begin{tabular}{|c|c|c|c|}
\hline & $\begin{array}{c}\text { Thermal } \\
\text { Cond } \\
W / \mathrm{m} / \mathrm{K}\end{array}$ & $\begin{array}{c}\text { Density } \\
\mathrm{k} / \mathrm{m}^{3}\end{array}$ & $\begin{array}{c}\text { Heat } \\
\text { Cap. } \\
\text { J/kg } K\end{array}$ \\
\hline SSI & 13.85 & 7888.7 & 460.44 \\
\hline SS2 & 15.95 & 8027.0 & 502.3 \\
\hline$D U$ & 25.54 & 19293 & 131.85 \\
\hline Pb & 35.13 & 11340 & 125.57 \\
\hline POLY & 0.1454 & 941.11 & 1925.5 \\
\hline$C C U$ & 16.45 & 1849.0 & 2164.0 \\
\hline
\end{tabular}

\section{RESULTS}

Since current spent fuel shipping cask designs are of two general typas and sizes as dictaled by the two major methods of tran:sportation, road and rail, it was determined that examinations of both a generic Truck Cask (TC) and a generic Rail Cast (RC) werc in order. The TC design and results will be discussed immediately, the RC will follow thereattei.

\section{A. Truck Cask Analysis}

The TC wa: I design appcars in Figure 4. The cask wall of this desi in consists of five laminations, three of Stainless Sroel (SS1), and one each of Depleted Uranium (DU) and Polyp:opylene (POLY). The stainless steel serves primarily as sonicural support, while the polypropylene is a neutron shield, and the depleted uranium accs as a gamma barrier. Figure 4, while not w scale, shows the dimensions of the cask wall as implemented in the subsequent analyses. An additional cask component not shown in Figure 4, which may or may not be presint, is a solar shield, which also acts as a personnel barrie: The thermal properties of the various malerials are cestural to the analysis which follows, so they are provided in ::able 1. Table 1 also includes thermal properties for th: RC design. Additionally, the subsequent analyses utilized an assumed convection coefficient of $h: 10 \mathrm{~W} / \mathrm{m}^{2} / \mathrm{K}$. This value is frequently cited for natural convection from horizontal plates. 27

The emissivities of the cask surface and the solar shield are nol known quantities, as cmissiviries typically vary considerably with material type and surface characteristics. it is expected that the emissivities of the cask surface and shield will exist in the range 0.3 to 1.0 . Differences in elnissiviry may cause significant changes in the relative in portance of the transient thermal behavior of the cask. These changes may result in a greater differenc: between the overall maximum temperature profile and the regulatory solution.

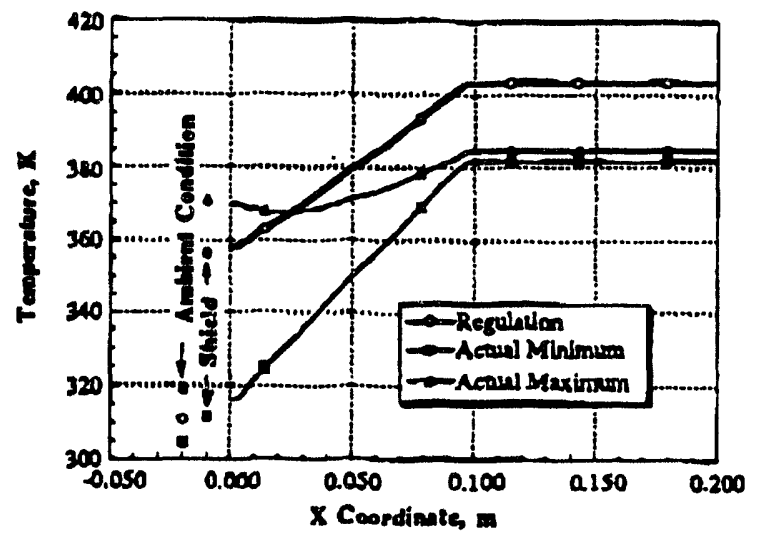

Figure 5: Truck Cask, Base Case

$$
\left(\varepsilon_{\text {purf }}=0.3, \varepsilon_{\text {anlete }}=1.0\right)
$$

A series of studies were underraken to find the values of emissivity which resulted in a worst case scenario for the TC. The goal of performing analyses on permutations of solar shield and surface emissivities is to find the casc in which the maximum portion of the cask wall is exposed to temperatures exceeding the regulatory calculation. It became evident that while all cases exhibit similar characteriscics, the worst case is that illustrated in Figure 5, a TC with a black solar shield and a gray cask surface $(\varepsilon=0.3)$. This case not only involves the largest portion of cask above the regulatory temperature, but it also involves the smallest margin of compliance in the interior region of the cask, where the maximum temperature is somewhat less than $20 \mathrm{~K}$ below the regulatory condition. The term "margin of compliance" refers to the temperature difference by which the regulatory solution exceeds the realistic solution at the interior boundary or the cask wall. Thus, Figure $S$ is identified as the base case for the remainder of the TC analysis, since it represents a worst-case scenario for the emissivity conditions.

The aciual profiles in Figure 5 were calculated by monitoring the tempcratures throughout the problem domain on the final, converged day of the simulation, and without regard to time of day, recording the minimum and maximum temperauures for cach node in the solution. The regulatory condition is truly steady-state, so no such bounding solutions are necessary. The maximum, minimum and regulatory values of the ambient temperafure and shield temperalure are also displayed in the plot however, litule atention should be paid to the $x$ coordinates of these data points, as their spatial positions are not strictly specified.

The general behavior demonstrated in Figure 5 is typical of most solutions for the TC. The amplitude of the diumal thermal wave is illustrated by the bounding minimum and maximum curves. It can be seen that the amplitude of the thermal wave decreases sharply in the region corresponding to the POLY neutron shield This is 


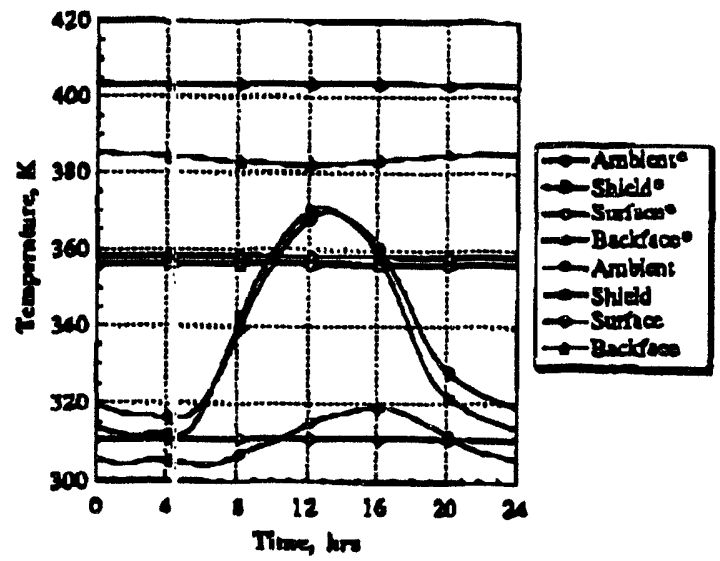

Figure 6: Truck Cask, Base Case, Diurnal Varintion for Realistic Simulation and Regulatory Conditions (")

due to the wave allenurting effect of materials with small thermal conducrivities. The immediately obvious information denionstrated by Figure 5 is that, for at least part of the day, the temperauure in the outer regions of the cask wall exceeits that temperaure which is predicted when the regulatory condition is applied. However, in the regions inside tive neutron shield, and for most of the neutron shield itself, the maximum temperanure is bounded by the regulatory condilion.

Figure 6 shrsws the temporal variation of temperature over a full twenly-four hours for the ambient condition, solar shield, casx surface and cask backface in a comparative anslysis of the generic truck cask. It is interesting $t 0$ nole in Figure 6 that the peak shield tempenure occurs just after noon, solar lime, while the ambient temperature peak is at four in the afternoon. This indicates that insolation dominates the environmental heat transfer effects, and that the high solar flux is strictly responsible for the brief period during which the shield and cask surface exceed the regulatory solution. The cask surface is seen is vary essencially in phase with the solar shield temperaturte; this is due to the inability of the surface to commiunicate thermal energy freely to the greaicst portion of the thermal mass of the cask, due 10 the insulating neutron shield. The plot in Figure 6 also demonstrates thit the backface never exceeds the regulatory solution in the base case. Furthermore, the peak backface temperature occurs at approximately midnight, which implies that the thermal waves require a full twelve hour: 10 propagate through the IC wall.

\section{B. Rail Cask Analysis}

The rail cask configuration is shown in Figure 7. The RC wall consiss of four laminations, two of which are a slightly different alloy of stainless steel from that used in the TC, hereafiter referred to as SS2. The neutron shield of the RC is composed of Concrete containing Copper fins (denoted sulsequently as $\mathrm{C} / \mathrm{Cu}$ ) to aide the transfer of

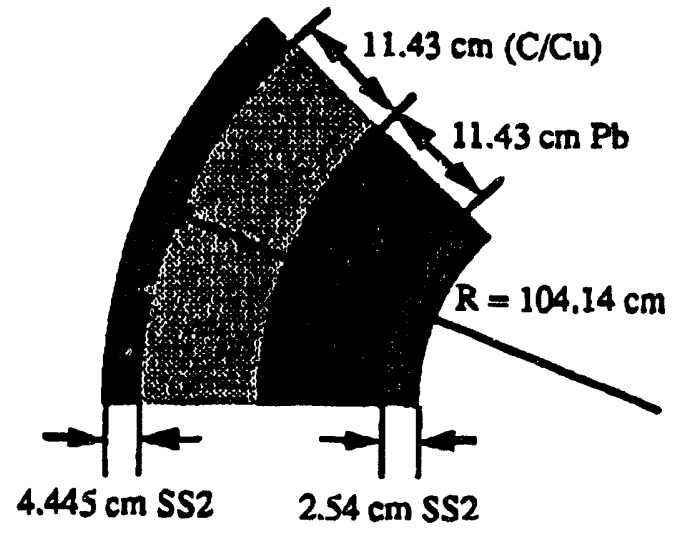

Drawing not w Scale

Figure 7: Schematic Drawing of Generic Rail Cask Wall

heat away from the spent fuel. The gamma shield is Lcad $(\mathrm{Pb})$. The dimensions of the various laminations, as well as the cask radius, appear in Figure 7.

Figure 8, the worst case for the RC, exhibits remarkably different characterislic temperature profiles as compared to those of the TC. The rather high thermal conductivity of the $\mathrm{C} / \mathrm{Cu}$ neutron shield leads not only to a decrease in the thermal wave attenuation of the wall, but it also allows the entire mass of the cask wall to absorb the energy associated with the thermal waves. The end result of these phenomena is that the encire cask wall lies below the calculared regulatory profile. Also of note is the very small slope of the temperature profiles in each of the figures; this is a direct result of the high thermal conductivity across the entire wall.

Figure 9 demonstrates explicilly some of the key fentures of the RC wall design. The main fcaturc of the RC, its higher thermal conductivity ncutron shield, causes two major changes in the phase shift of the propagating thermal wavcs. First, the ability of the cask surface to communicate with the entire cask wall thermal inass allows the peak temperature of the surface to occur about three hours after the peak solar shicld temperaure. Additionally, the backface temperature is now more closely in phase with the surface tempcrature, with a phase lag of about two hours, because of the small time constant of the composite wall. The importance of these effects is in the fact that the entire cask wall absorbs and diminishes the effect of the diumal transient, so that the surface temperature is now very much lower than the regulatory temperature, at all times.

Several other analyses were performed in order to examine the behavior of the TC and RC having introduced differences in cask geometry and composition. These analyses are presented in the report. ${ }^{3}$ In general, it 


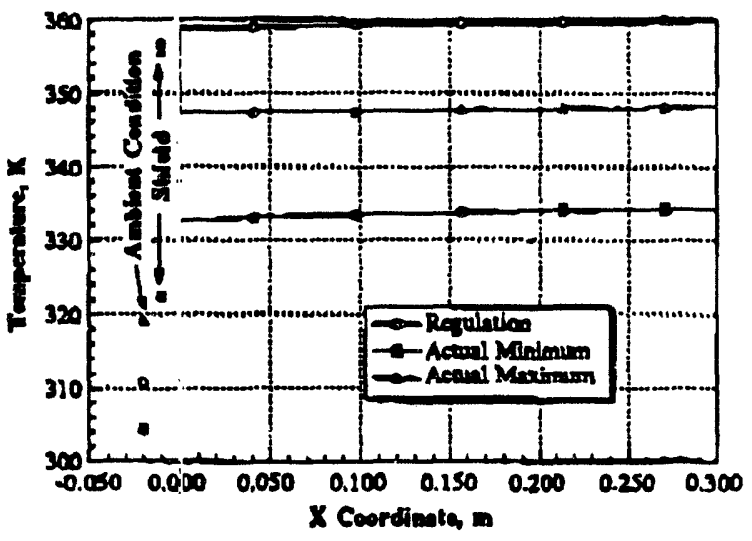

Figure 8: Rail Cask, Base Case

$$
\left(\varepsilon_{\text {uur }}=0.3, \varepsilon_{\text {suled }}=1.0\right)
$$

was found that the base cases are representative of the behavior ercourtered for a wide varicty of cask configurations. It was demonstraced that the maximum temperaures in the outer regions can exceed the corresponding nigulatory solutions, but only by a few more degrees thin the TC base case, at worst.

\section{CONCLUSIONS}

The simulations performed in the course of this analysis have consistendy and uniformly shown that the interior maximum wall temperatures of both the TC and RC fall well boliow those predicted when the steady-state implementation of the regulatory model is used. It has been shown that maximum temperarures near the surface of some cask detigns, and at the solar shield, occasionally lie slightly abovi; the regulatory prediction. These temperaure diffirences are small and of shor duration. It is also pointed out that the "realistic" conditions utilized in this study are conservative, as the temperature condition and the insolation condition are taken from two different locations, each the worst case out of all the available data. This means that while either condition may be encountered in principle. both conditions have never been observed to occir simultaneously. This conservativity enfores the calculated solutions as wonst cast limitations. Since this diums l model is bounding, it is expected that no real situation: will develop in which maximum wall temperatures exceed the regulatory calculation.

The analyse; have made it clear that diumal temperature variations which penctrate the cask wall have maxima substantially less then the corresponding regulatory solutinns. Therefore, it is likely that vital cask structural companents located interior to the neutron shielding, and ths spent fuel itself, will not excoed the temperatures calp:ulated even when a transient interpretation of 10CFR71 is used. However, this is not necessarily the cilse with regard to the ourer regions of the cask wall. Therefore, some caution must be used in the

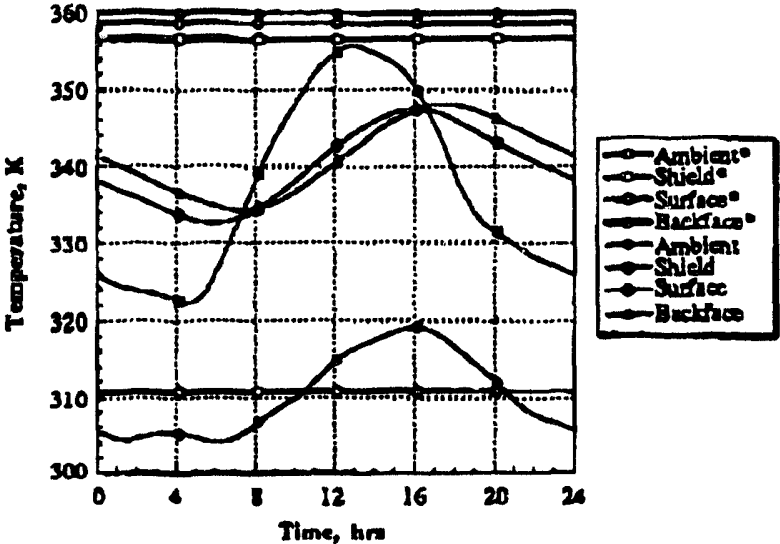

Figure 9: Rail Cask, Base Case, Diurnal Variation for Realistic Simulation and Regulatory Conditions (*)

evaluation of cask designs where external temperanures excecd regulatory limits predicted using a transient interpretation of 10CFR71. Particularly of interest is the temperature restriction involving the accessible surface of the cask. Care must be taken to ensure that proper levels of conservatism are used in such calculations, or it is conceivable that actual casks that meet the accessible surface limitation under the regulatory normal day conditions may fail to meet the same condition under circumstances involving real days with extreme temperatures and high insolation levels.

Finally, it was determined that the key factor in calculating the cask response to ambient conditions is the material composition of the neutron shield. Unlike typical structural materials (metals), and gamma shields (heavy metals), neutron shields can be made of quite a large variety of materials, having a wide range of thermal properties. Investigations using two potential shield choices, POL $Y$ and $C / C u$, revealed a large variation in cask response between the materials. Furthermare, it was found that POLY is the limiting case as it may cause extemal transient temperatures to exceed those calculated using the regulatory normal condition by the largest margin observed, although internal temperatures remain below Llose predicted for the regulatory condition.

\section{NOMENCLATURE}

$\alpha \quad$ Thernal Diffusivity, $\mathrm{m}^{2} / \mathrm{s}$

c Specific Heal, J/kg/K

a Partial Differential Operator, unity

$\Delta \quad$ Diffurence Operator, unity

$\varepsilon \quad$ Emissivity, unity

h Convection Heal Transfer Coefficient, $W / m^{2} / K$

k Thermal Conductivity, $W / \mathbf{m} / \mathbf{K}$

q"' Volumetric Heat Gcneration, W/m ${ }^{3}$

$q^{\prime \prime} \quad$ Heat Flux, W/m $\mathbf{m}^{2}$

I Radial Position, $m$

$p \quad$ Density, $\mathrm{kg} / \mathrm{m}^{3}$ 
$t$ Tempẹranu, $K$

L. Ambiene Temperature, $K$

h. Ampliurde of Temperanure Cycle, $\mathbf{k}$

4 Analytical Temperature Solution, $K$

$t_{\mathrm{a}} \quad$ Numerical Temperature Solution, $\mathrm{K}$

i Mean ilemperature, $\mathbf{K}$

I Toral Jime. 5

$\tau$ Time, ii

0 Angulkir Frequency, rad/s

$X$ Total I:ength. $m$

\section{REFERENCES}

1. Lake, W. B., "Modeling the Normal Therma Environmeit," Broceedinos of the 6in Intermational Sympostumpion Packagine and Transportation of Radiogctivs: Marerials, pp. 1090-1097, West Berlin. November $10-14,1980$.

2. Brown, N. IN.. Gianoulakis, S. E., Lake, W. H., Compariso L of 10 CFR 71 Normal Day Conditions With Bounsline U. S. Hor Day Exrremes, Sandia National Liboratories, SAND91-2255C, 1992.

3. Quinlan, F.T., Iypical Mereomlogical Year User's Manual National Climatic Data Center, Asheville, North Caro|ina, May, 1981.

4. Press, W. H., Flannery, B. P., Teukolsky, S. A., Vetrerling, W. T., Numerical Recipes, FORTRAN Version, Cambridge University Press, 1989.

5. Manson, S. J., Gianoulakis, S. E., A Comparison of Spent Euel ihiopine Cast Response to 10 CER 71 Nomal Conditions and Realistic. Hot Day Exuremes, Sandia National Laboratories, SAND93-1771, to be published.

6. Gebhar, B. Heal Conduclion and Mass Diffusion. McGraw-H:11 Inc., 1993.

7. Incropera F. P., DeWitt, D. P., Eundamentals of Heat and Mass Iransfer, Second Edition, John Wiley \& Sons, 1381.

\section{DISCLAIMER}

This report was prepared as an account of work sponsored by an agency of the United States Government. Neither the United States Government nor any agency thereof, nor any of their employees, makes any warranty, express or implied, or assumes any legal liability or responsibility for the accuracy, completeness, or usefulness of any information, apparatus, product, or process disclosed, or represents that its use would not infringe privately owned rights. Reference herein to any specific commercial product, process, or service by trade name, trademark, manufacturer, or otherwise does not necessarily constitute or imply its endorsement, recommendation, or favoring by the United States Government or any agency thereof. The views and opinions of authors expressed herein do not necessarily state or reflect those of the United States Government or any agency thereof. 

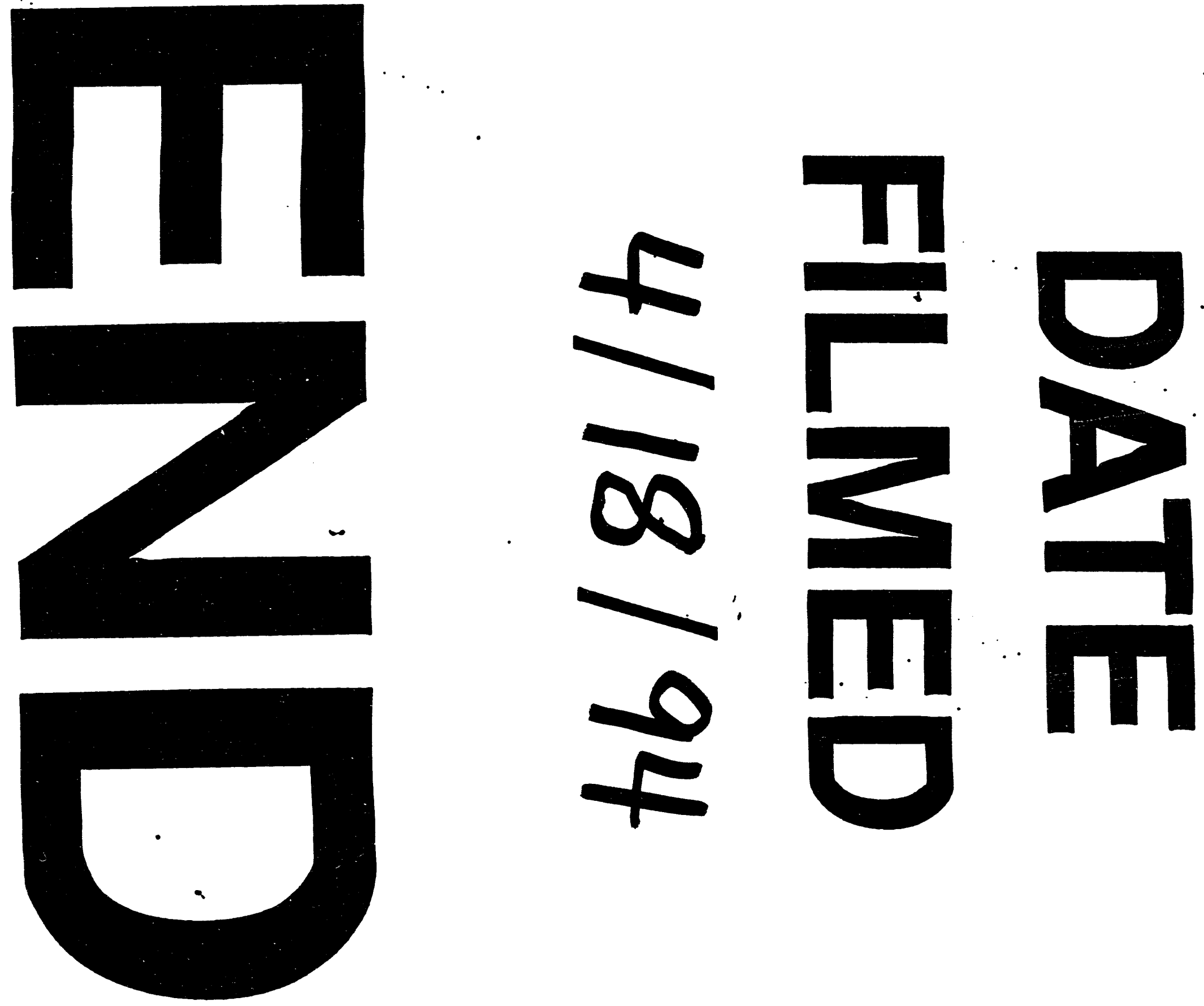
$-$ 